\title{
Gambaran Teknik Menyikat Gigi dan Indeks Plak pada Siswa SD GMIM Siloam Tonsealama
}

\author{
${ }^{1}$ Princess Keloay \\ ${ }^{1}$ Christy N. Mintjelungan \\ ${ }^{2}$ Damajanty H. C. Pangemanan
}

\author{
${ }^{2}$ Program Studi Pendidikan Dokter Gigi Fakultas Kedokteran \\ ${ }^{2}$ Bagian Fisiologi Fakultas Kedokteran \\ Universitas Sam Ratulangi Manado \\ Email: keloayp@gmail.com
}

\begin{abstract}
In Indonesia, children dental and mouth health is on the apprehensive level. The caries prevalence in children of 5 to 9 years old is $92.6 \%$ and the proportion of brushing their teeth properly is only $1.4 \%$. The control and prevention of plaque forming can be done in a simple, effective, and practical way through brushing the teeth thoroughly and regularly. This study was aimed to obtain the tooth brushing technique and plaque index among students at SD GMIM Siloam Tonsealama (elementary school). This was a descriptive study with a cross sectional design. Study population consisted of elementary students og grade 3 to 5 . We used total sampling method. There were 42 students as subjects. Data were obtained by observing their tooth brushing techniques. The results showed that all students used combination technique of tooth brushing. Most students had plaque index of moderate category. The mean plaque index of the subjects was 2.67. In conclusion, students at GMIM in Tonsealama used combination technique of tooth brushing, and their plaque index was categorized as moderate.

Keywords: plaque index, brushing teeth technique
\end{abstract}

\begin{abstract}
Abstrak: Kesehatan gigi dan mulut anak di Indonesia masih sangat memrihatinkan. Prevalensi karies pada anak usia 5-9 tahun dilaporkan mencapai 92,6\%, dan proporsi waktu menyikat gigi dengan benar sebesar $1,4 \%$. Usaha untuk mengontrol dan mencegah pembentukan plak dapat dilakukan secara sederhana, efektif, dan praktis yaitu dengan cara menggosok gigi secara teliti dan teratur. Penelitian ini bertujuan untuk mengetahui gambaran teknik menyikat gigi dan indeks plak siswa SD GMIM Siloam Tonsealama. Jenis penelitian ialah deskriptif dengan desain potong lintang. Populasi penelitian terdiri dari siswa sekolah dasar kelas 3 sampai dengan 5. Pengambilan sampel menggunakan total sampling. Terdapat sebanyak 42 siswa sebagai subyek penelitian. Pengumpulan data menggunakan formulir pemeriksaan. Hasil penelitian menunjukkan bahwa teknik menyikat kombinasi digunakan oleh seluruh subyek. Indeks plak paling banyak pada kategori sedang. Rerata nilai indeks plak yaitu 2,67. Simpulan penelitian ini ialah teknik menyikat gigi yang digunakan oleh siswa SD GMIM di Tonsealama ialah teknik kombinasi dengan indeks plak tergolong kategori sedang
\end{abstract}

Kata kunci: indeks plak, teknik menyikat gigi

Kesehatan gigi dan mulut anak di Indonesia masih sangat memrihatinkan sehingga perlu mendapatkan perhatian yang serius dari tenaga kesehatan. Data yang dirilis Departemen Kesehatan (Depkes) dari Riskesdas 2018 mencatat proporsi masalah gigi dan mulut di Sulawesi utara sebesar $66,5 \%$ dan yang mendapatkan pelayanan dari tenaga medis gigi sebesar 9,4\%. Di Indonesia prevalensi karies pada anak usia 5-9 tahun yakni 92,6\%, dan proporsi waktu menyikat gigi dengan benar sebesar $1,4 \%{ }^{1}$ 
Penyebab utama karies yaitu adanya akumulasi plak berkaitan dengan kebersihan mulut yang buruk. Plak merupakan penyebab utama terjadinya penyakit gigi maupun penyakit gusi. Pada gusi lapisan plak dapat menyebabkan radang gusi atau gingivitis. $^{2}$

Cara pencegahan karies gigi ialah mengusahakan agar pembentukan plak pada permukaan gigi dapat dibatasi dengan cara mencegah pembentukan atau membersihkan plak secara teratur. Usaha untuk mengontrol dan mencegah pembentukan plak dapat dilakukan secara sederhana, efektif dan praktis yaitu dengan cara menggosok gigi secara teliti dan teratur dapat menghilangkan plak dari seluruh permukaan gigi, terutama permukaan interproksimal sangat penting untuk pemeliharaan kesehatan gigi dan mulut. Ketebalan plak berada di interproksimal, restorasi yang kasar, pit, dan fisur gigi, serta gigi yang berjejal. ${ }^{3}$

Mengggosok gigi dapat mengurangi tingkat plak. Dengan menggosok gigi selama 180 detik dapat menghapus plak 55\% lebih banyak dibandingkan menggosok gigi selama 30 detik. Menggosok gigi selama 120 detik dapat menghapus plak 26\% lebih banyak dibandingkan menggosok gigi selama 45 detik. $^{4}$

Perilaku menggosok gigi pada anak harus dilakukan dalam kehidupan seharihari tanpa ada perasaan terpaksa. Kemampuan menggosok gigi secara baik dan benar merupakan faktor yang cukup penting untuk perawatan kesehatan gigi dan mulut. Keberhasilan menggosok gigi juga dipengaruhi oleh teknik menyikat gigi yaitu teknik vertikal, horizontal, sirkular, Charter, Stillman-McCall, Bass, dan fisiologi. ${ }^{5}$

Mengingat masih tingginya prevalensi karies pada anak di Indonesia, maka peneliti tertarik untuk mengetahui gambaran teknik menyikat gigi dengan indeks plak pada siswa SD GMIM Siloam Tonsealama.

\section{METODE PENELITIAN}

Penelitian ini dilakukan pada bulan April 2019 di Sekolah Dasar GMIM Siloam di Desa Tonsealama Kecamatan Tondano
Utara, Kabupaten Minahasa, Provinsi Sulawesi Utara. Jenis penelitian ialah deskriptif dengan desain potong lintang. Populasi penelitian terdiri dari anak sekolah dasar kelas 3, 4, dan 5 di Sekolah Dasar tersebut. Berdasarkan survei awal, didapatkan jumlah siswa sebanyak 42 anak. Teknik pengambilan sampel yaitu total sampling.

Kriteria inklusi ialah: bersedia menjadi responden penelitian dibuktikan dengan adanya informed consent, minimal memiliki dua gigi indeks, hadir saat penelitian, dan siswa kooperatif. Kriteria eksklusi ialah: orang tua tidak menyetujui dan subyek tidak kooperatif saat penelitian berlangsung. Variabel penelitian ini ialah teknik menyikat gigi dan indeks plak.

Indeks yang digunakan yaitu indeks plak. Menurunkan indeks plak ialah kemampuan subyek dalam menurunkan indeks atau nilai plak yang dihitung dengan menggunakan indeks PHP, yaitu dengan cara mahkota gigi pada bagian fasial atau lingual dibagi menjadi lima bagian, yaitu distal (d), mesial $(\mathrm{m})$, sepertiga tengah gingival $(\mathrm{g})$, sepertiga tengah (c), sepertiga tengah insisal atau oklusal (i/o) dengan nilai 1 = ada plak dan nilai $0=$ tidak ada plak. Kemudian nilai plak dijumlahkan dan dibagi jumlah gigi yang diperiksa sehingga diperoleh kategori: Sangat baik $=0$; baik $=0,1-1,7$; sedang $=$ $1,8-3,4$; buruk $=3,5-5$. $^{2}$

Teknik menyikat gigi terdiri dari teknik menyikat gigi secara kombinasi yaitu teknik dengan menggabungkan teknik horizontal (kiri-kanan), vertikal (atas-bawah) dan sirkular (memutar). Teknik menyikat gigi secara vertikal adalah teknik menyikat gigi dengan gerakan vertikal dimulai pada rahang atas dimana gerakan penyikatannya dari atas ke bawah dan pada rahang bawah gerakannya dari bawah ke atas. Teknik horizontal adalah teknik menyikat gigi dengan arah horizontal ke kiri dan ke kanan. Teknik ini biasanya dianjurkan pada anak-anak dan gerakannya dalam arah horizontal pada permukaan oklusal gigi. Teknik fones (sirkuler) adalah teknik yang gerakan menyikat secara memutar pada arah gingiva dan permukaan gigi. ${ }^{4}$

Instrumen penelitian ialah formulir 
pemeriksaan indeks plak. Alat dan bahan yaitu kaca mulut, pinset, alkohol, masker, handscoon, sikat gigi, pasta gigi, dan disclosing solution.

Penelitian ini dilakukan setelah mendapat persetujuan dari Koordinator Program Studi Pendidikan Dokter Gigi Universitas Sam Ratulangi Manado dan kepala Sekolah Dasar GMIM Siloam desa Tonsealama. Orang tua siswa yang menjadi subyek penelitian diminta untuk mengisi informed consent. Peneliti memeriksa indeks plak dari subyek kemudian ditulis dalam formulir pemeriksaan. Pengolahan data dengan menggunakan program komputer.

\section{HASIL PENELITIAN}

SD GMIM Siloam merupakan Sekolah Dasar yang berlokasi di desa Tonsealama, Kecamatan Tondano Utara, Kabupaten Minahasa. Sekolah ini memiliki jumlah total siswa 96 yaitu 41 siswa dan 55 siswi. Total guru yang ada di sekolah ini sebanyak 8 orang terdiri dari 6 PNS dan 2 guru honorer. Penelitian ini dikategorikan berdasarkan jenis kelamin, teknik menyikat gigi, dan hasil pemeriksaan indeks plak.

Subyek penelitian ini berjumlah 42 anak yang berada di kelas 3, 4, dan 5, terdiri dari jenis kelamin laki-laki sebanyak 17 anak $(40,48 \%)$ dan jenis kelamin perempuan sebanyak 25 anak $(59,52 \%)$.

Tabel 1 menunjukkan bahwa subyek yang menyikat gigi menggunakan teknik kombinasi ialah 42 anak (100\%) sedangkan yang menyikat gigi secara vertikal, horizontal, dan fones (sirkular) tidak ada.

Tabel 1. Distribusi subyek berdasarkan teknik menyikat gigi

\begin{tabular}{ccc}
\hline Teknik menyikat gigi & $\mathrm{N}$ & $\%$ \\
\hline Vertikal & 0 & 0 \\
Horizontal & 0 & 0 \\
Fones (sirkular) & 0 & 0 \\
Kombinasi & 42 & 100 \\
\hline
\end{tabular}

Tabel 2 menunjukkan bahwa kategori indeks plak yang paling banyak ditemukan yaitu kategori indeks plak sedang sebanyak 27 anak (64,29\%), diikuti kategori indeks plak baik yaitu 14 anak $(33,33 \%)$, dan kategori indeks plak buruk yaitu 1 anak $(2,38 \%)$. Rerata indeks plak seluruh subyek penelitian ialah 2,67 dengan kategori sedang.

Tabel 2. Hasil pemeriksaan berdasarkan kategori indeks plak responden

\begin{tabular}{ccc}
\hline Kategori indeks plak & $\mathbf{N}$ & $\mathbf{\%}$ \\
\hline Sangat baik & 0 & 0 \\
Baik & 14 & 33,33 \\
Sedang & 27 & 64,29 \\
Buruk & 1 & 2,38 \\
Total & 42 & 100,00 \\
\hline
\end{tabular}

\section{BAHASAN}

Distribusi subyek penelitian menunjukkan jenis kelamin perempuan $(59,52 \%)$ lebih banyak dari laki-laki (40,48\%). Perkembangan pada anak baik laki-laki maupun perempuan terjadi karena faktor kematangan, belajar atau pengalaman, faktor-faktor dalam (bawaan), dan faktor luar (lingkungan). ${ }^{6,7}$

Tabel 1 menunjukkan bahwa teknik menyikat gigi dengan menggunakan teknik kombinasi yang digunakan oleh seluruh subyek $(100 \%)$. Tidak didapatkan subyek yang menggunakan teknik menyikat gigi vertikal, horizontal, dan fones. Berdasarkan penelitian yang dilakukan oleh Suyatmi et al, ${ }^{8}$ sikat gigi metode kombinasi paling efektif menurunkan skor plak. Para ahli juga menyimpulkan bahwa cara menyikat gigi yang paling efektif yaitu dengan mengombinasikan semua metode yang ada. ${ }^{8}$

Tabel 2 menunjukkan bahwa ketegori indeks plak yang paling banyak ditemukan yaitu kategori indeks plak sedang $(64,29 \%)$, disusul oleh kategori indeks plak baik $(33,33 \%)$, dan kategori indek plak buruk $(2,38 \%)$. Masalah gigi anak yang sering terjadi disebabkan bila anak belum bisa membersihkan atau menyikat gigi dengan baik. Gigi berlubang merupakan salah satu masalah yang sering dikeluhkan anak. Penyebabnya yaitu plak yang tidak dibersihkan sehingga muncul bakteri yang merugikan bagi gigi dan mulut. Cara yang paling sederhana untuk menjaga kebersihan 
gigi dan mulut yaitu dengan cara menyikat gigi. Penelitian yang dilakukan oleh Suyatmi et $\mathrm{al}^{8}$ di SD Muhammadiyan Trini Yogyakarta menjelaskan bahwa menyikat gigi menggunakan teknik kombinasi peling efektif menurunkan skor plak. Selain itu gigi yang disikat kurang dari 2 menit tidak efektif membersihkan plak. Menyikat gigi yang tepat membutuhkan waktu minimal 2 menit. ${ }^{9,10}$

Rerata indeks plak seluruh responden siswa SD GMIM Siloam di Tonsealama ialah 2,67 dengan kategori sedang. Hasil penelitian Unkel et $\mathrm{al}^{11}$ menyatakan usia kronologis merupakan prediktor yang beralasan untuk kemampuan menyikat gigi. Pada anak usia lebih muda dari usia 10 tahun, kurang memiliki kemampuan ketrampilan fisik untuk menyikat gigi. Ketrampilan menyikat gigi lebih baik pada anak yang lebih tua, yaitu sekitar usia 10 tahun. Selain metode menyikat gigi dapat berpengaruh terhadap penyingkiran plak, faktor usia juga sangat berpengaruh terhadap kemampuan anak dan penyikatan gigi. Semakin meningkat usia anak, semakin baik kemampuan motoriknya dan semakin baik pula gerakan dalam penyikatan gigi. ${ }^{12}$ Oleh karena itu pemilihan metode menyikat gigi perlu diketahui, sesuai dengan kemampuan motorik dan usia anak. Dengan pemilihan metode yang tepat, hasil penyingkiran plak dapat lebih optimal. Dengan demikian kebersihan mulut juga lebih baik. ${ }^{13}$

\section{SIMPULAN}

Berdasarkan hasil penelitian siswa SD GMIM di Tonsealama ini dapat disimpulkan bahwa teknik menyikat gigi yang digunakan oleh ialah teknik kombinasi dengan indeks plak rerata tergolong kategori sedang.

Bagi orang tua disarankan agar membantu anak-anak dalam menjaga dan merawat kebersihan gigi dan mulut anak dengan cara menyikat gigi 2 kali sehari yaitu pagi sesudah sarapan dan malam sebelum tidur. Menyikat gigi yang tepat membutuhkan waktu minimal 2 menit. Bagi pihak sekolah disarankan agar dapat bekerja sama dengan Dinas Kesehatan agar lebih meningkatkan status kebersihan gigi dan mulut dengan cara memberikan penyuluhan tentang masalah kesehatan gigi dan mulut serta mengajari anak untuk menyikat gigi yang baik dan benar.

\section{DAFTAR PUSTAKA}

1. Riset Kesehatan Dasar (RISKESDAS). Badan Penelitian dan Pengembangan Kesehatan Kementerian Kesehatan RI. Jakarta, 2018.

2. Houwink B, Backer DO, Cramwinckle AB. Ilmu Kedokteran Gigi Pencegahan. Sutatmi S, Indirawati, Tjahya, Sintawati, Tince, penerjemah Yogyakarta: Gadjah Mada University Press, 1994; p. 114.

3. Zulkarnain RAA, Riyanti E, Sasmita IS. The differences of caries prevalence and caries index of children in primary school with UKSG in Kota Batam. Bandung. Padjajaran Journal of Dentistry. 2009;21(1):36.

4. Creeth JE, Gallagher A, Sowinski J, Bowman J, Barrett K, Lowe S, et al. The effect of brushing time and dentifrice on dental plaque in vivo. Journal Dental Hygiene. 2009;83(3):6.

5. Cuqini AM, Thompson M, Warren RP. Correlation between two plaque indices in assesment of toothbrush effectiveness. J Contemp Dent Pract. 2006;7(5): $1-9$.

6. Dwijandono SEW. Psikologi Pendidikan. Jakarta: Grasindo, 2002; p. 71.

7. Gunarsa SD. Dasar dan Perkembangan Teori Anak. Jakarta: 2008; p. 31.

8. Suyatmi D, Sari R, Yuniarly E. Sikat gigi metode kombinasi efektif menurunkan skor plak. Journal Teknologi Kesehatan. Yogyakarta. 2013;9(2):67-8.

9. Ardyan GR. Serba Serbi Kesehatan Gigi dan Mulut (Cetakan 1). In: Handayani NP, penyunting. Jakarta: EGC.2010; p. 24.

10. Hiremath SS. Textbook of Preventive and Community Dentistry (2nd ed). India: Elsevier, 2011; p. 201, 415.

11. Unkel JH, Fenton,S.J, Hobbs.G. Frere C.L. Toothbrushing ability is related to age in children. ASDC J Dent Child. 1995;62(5):346-8.

12. Rifki A, Hermina T. Perbedaan efektivitas menyikat gigi dengan metode roll dan horizontal pada anak usia 8 dan 10 tahun di Medan. Cakradonya Dent J. 
80 Jurnal e-Gigi (eG), Volume 7 Nomor 2, Juli-Desember 2019

2016;8(1):4.

13. Wiradona I, Bagoes W, Syamsulhuda B.M.

Pengaruh perilaku menggosok gigi

terhadap plak gigi pada siswa kelas IV dan V di SDN Wilayah Kecamatan Gajahmungkur Semarang. Jurnal Promosi Kesehatan Indonesia. 2013; 8(1): 59-68. 